\title{
Mental Models and Dynamic Capabilities in a Brazilian Family Company
}

\author{
Rubens Mussolin Massa ${ }^{1}$ \\ rmussolin@uol.com.br | (D)0000-0003-4724-3491 \\ Tales Andreassi ${ }^{1}$ \\ tales.andreassi@fgv.br | (D)0000-0002-7636-3014 \\ Jeferson Lana ${ }^{2}$ \\ jlana@univali.br | (D)0000-0002-9787-1114 \\ Franciane Reinert Lyra ${ }^{2}$ \\ francianel@univali.br | (DD0000-0003-1505-6739
}

\begin{abstract}
This article analyzes how the concepts of paradigm, organizational culture, and cognition of resources influence the mindset of managers and skew the choice of which dynamic capabilities should be developed by an organization, in the process of innovation and change. A case study was carried out that examined a traditional 64-year-old family publishing house. In-depth interviews with the company's partners were conducted, as well as a documental analysis. The results revealed that organizational paradigms skew the choice of which dynamic capabilities should be developed, prioritizing those that are in accordance with the organizational paradigm. Therefore, the organization tends to be aligned with its own paradigm, rather than aligning with context. It demonstrates the importance of the organizational paradigm, organizational culture, and cognition of resources in the mindset of managers. Throughout periods of innovation and change, those aspects may influence the decisionmaking process in the organization. This is considered a relevant aspect of understanding how some small businesses survive environmental changes while others succumb to them.
\end{abstract}

\section{KEYWORDS}

Dynamic capabilities; Innovation; Mental models. Family business.

\footnotetext{
${ }^{1}$ Fundação Getulio Vargas Escola de Administração de Empresas de São Paulo, São Paulo, SP, Brasil

${ }^{2}$ Universidade do Vale do Itajaí, Itajaí, SC, Brasil

Received: 01/21/2019.

Revised: 07/15/2019.

Accepted: 09/02/2019.

Published Online: 03/23/2020.

DOI: http://dx.doi.org/10.15728/bbr.2020.17.3.3
} 
BBR

17

294

\section{INTRODUCTION}

Organizational innovation involves, over time, the change of organizational resources and skills, followed by the renewal of products (Floyd and Lane, 2000). The concept of dynamic capabilities refers to the company's ability to renew itself in terms of environmental changes (Teece et al., 1997) and when it comes to survival in a dynamic environment, dynamic capabilities are considered as a foundational basis (Wang, 2016). Based on that, some studies have systematically investigated the relationships between dynamic and innovation capabilities for sustained competitiveness (Breznik and Hisrich, 2014).

Considering dynamic capabilities as the internal processes of a company, it is assumed here an empirical organizational lens, not an economic one (Barney, 1991 apud Eisenhardt and Martin, 2000). It is also emphasized that dynamic capabilities are not tautological and vague as it has been discussed, but are well-known processes involving alliances, product development and strategic decision - concepts studied apart from traditional RBV, but of valuable contribution to the studies on competitive advantage, for their ability to create, integrate, recombine, and save resources (Eisenhardt and Martin, 2000).

This article is based on classical and contemporary studies on dynamic capabilities and on a literature review of strategic changes (Quinn, 1980; Grinyer and Spender, 1979; Pettigrew, 1985; Johnson, 1992) in order to argue and demonstrate empirically, through the case study of a publishing house family firm, as the organizational paradigms skew the choice of which dynamic capabilities should be developed in organizations, causing an alignment of these with their own paradigms, to the detriment of the real demands of the environment. This case study empirically demonstrates the importance of the organizational paradigm, organizational culture, and cognition of resources in the mindset of managers. Throughout periods of innovation and change, those aspects may influence the decision-making process in the organization. That is considered a relevant aspect of understanding how some small businesses survive environmental changes while others succumb.

As the theoretical contribution of the study, it is presented that few studies demonstrate dynamic capabilities through case studies; of those who do, few discuss what are and are not dynamic capabilities, studying any form of innovation ad-hoc problem solving (Winter, 2003) as an exercise of dynamic capability, which is beyond the approach of the theoretical concept. Instead, this article is concerned to discuss such theoretical confusion, trying to elucidate it. Still, the practical contribution is relevant. This study empirically demonstrates the importance of organizational paradigms in the decision-making process as to which dynamic capabilities the organization develops or which is a major factor in the study on why some organizations survive to see environmental change while others succumb. The analysis makes clear that the organizational paradigms skew the choice of which dynamic capabilities should be developed and, as a result, leave the organization in line with its own paradigms rather than readjust to environmental reality.

\section{THEORETICAL FRAMEWORK}

\subsection{Operating Mechanisms of Dynamic Capabilities}

According to Winter (2003), dynamic capabilities are similar to organizational capabilities, which he defines as a collection of routines, along with inputs in the execution flow, which provide 
the management of an organization a range of strategic decisions in order to produce significant outputs of a particular type, which implies the inexistence of dynamic capability if there is no established goal. Thus, there is an important discussion about what dynamic capabilities are and are not. Winter (2003) uses an ad-hoc problem-solving expression to refer to behavior change movements in time that are not dynamic capabilities, i.e., which are not routines, which do not follow patterns, and which are not repetitive.

Some of the key learning mechanisms on dynamic capabilities are repeated practice; encoding of experience, errors, and the speed of the experiences. Repeated practice, as demonstrated by many empirical studies (Zollo and Singh, 1998), combined with the encoding of experience in new technologies and procedures make the experience more applicable by its facility and potencializes the celerity of the construction of corporative routines (Argote, 1999). Studies of errors also show that these, when large and strategic, impose barriers to managers' action, whereas, when small, they encourage internal learning in organizations through readjustment in order to correct it (Eisenhardt and Sull, 2001). The speed of the experiences also affects the dynamic capabilities: very intense experiences do not allow managers to turn them into significant learning and uncommon experiences can lead to neglecting what has been learned previously. The output is a noncumulative knowledge (Argote, 1999; Pedron et al., 2018; Tondolo and Bitencourt, 2014).

\subsection{THE DEFINITION OF THE ROUTINES MODERATED BY MARKET DYNAMICS}

Routines in the development process of dynamic capabilities, in an enlarged view of a routine process (Cyert and March, 1963; Nelson and Winter, 1982), can be moderated by the dynamics of the market studied. Studies have shown that organizations with well-structured processes are capable of producing goods faster; however, these are often not in line with market demands (Fredrickson, 1984; Eisenhardt and Tabrizi, 1994). Yet, companies without any structure, with organic processes, are also ineffective (Brown and Eisenhardt, 1997). It is known that, as knowledge is obtained in this process, to make it more effective, it tends to turn it into progressively more formal routines in order to achieve the objective more effectively.

The relationship can be explained as follows: the mainstream literature on the subject theorizes that, in markets with moderate dynamics, where changes occur frequently, following linear and predictable patterns, and that competitive conditions are well defined, managers are able to work with a view to history and develop structured plans (Helfat, 1997). However, in very dynamic markets, i.e. those whose market boundaries are not clear and there are no clearly successful business models, market players are ambiguous and are less predictable (Eisenhardt, 1989), so that changes tend to be non-linear and less predictable. It is noted that even in these conditions it is important to consider routines that allow decisions not to be disrupted and proceed organicly, drawing on simpler procedures focused on core aspects, but able to generate few effective rules to specify borders of action and determine priorities. In this context, the use of experiments that generate rapid learning supplies the lack of highly structured procedures, using prototypes capable of generating and obtaining more knowledge, in order to properly support strategic decisions in order to build new effective resources in creating new competitive advantages (Argote, 1999; Sitkin, 1992).

\subsection{The BIAS IN THE DEVELOPMENT DECISION OF DYNAMIC CAPABILITIES}

Such statements, however, do not explain fully why some organizations are able to renew themselves in the face of environmental changes while others succumb, leaving important 
BBR

17

296

theoretical gaps. As Danneels (2010) points out, what is done in the performance of dynamic capabilities depends on the cognition of the executives on the resources of the firm. The author demonstrates, through an empirical application, that what a company can make is directly linked to the managers' view of the organization, since the mental model of executives influence in identifying resources, having an understanding of its fungibility and the direction the organization must follow, as well as other relevant dimensions.

This is what the author termed the 'resources scheme', i.e., simplifying mental models of reality that managers adopt in their companies for resource management. Such models contain answers to questions that will lead to the application of resources in accordance with a particular vision and logic but may omit important and decisive details in the organization's directions.

Thus, it is important to pay attention not only to the issues discussed in the literature on dynamic capabilities but also the political and socio-cultural issues that influence the choice of which dynamic capabilities should be developed so that they are committed and aligned with the environment and not only the paradigm of the organization. This may explain, for example, why in research cited by Brown and Eisenhardt (1997) companies with well-structured processes were capable of producing products faster, although these are not often in line with market demands.

\subsection{LINKS TO STRATEGY AND ORGANIZATIONAL CULTURE}

As pointed by Johnson (1992), a significant amount of work was developed during the eighties linking the intercept of strategy and organizational culture. Much of this research had focused on the problems involving the inertial nature of strategy and the need for managers to control the cultural context (Lynch and Mors, 2019) in order to pursue strategic changes that enabled and sustained changes to long-term success. One of the important points in this process is to consider the implications of managers' actions.

In low dynamic markets, changes tend to be incremental, as in the concept of logical incrementalism, which means that, over long periods, the strategy will be developed incrementally and the past has great relevance in the way the company shapes the future (Quinn, 1980). However, there are other explanations for how patterns emerge. Studies in strategic management point out that decisions emerge from the managerial discretion for internal and external incentives in a social and political environment (Johnson, 1992); thus, it is reasonable to say that the strategic orientation is directly related to the assumptions, values, and beliefs present in the organizational experience of its managers and current organizational culture.

If there are individual interpretations, somehow, there is also a set of shared beliefs among managers, called a paradigm (Schein, 1986), which is to act unconsciously at the deepest level of beliefs and assumptions among managers, forming views taken for granted that shape the way the organization sees itself and the environment. Thus, by its nature, the paradigm is a present cognitive structure, to a greater or lesser extent, within all organizations. This allows the organization to internalize their unique skills and special abilities that will be the basis to achieve competitive advantages (Johnson, 1992). However, these elements can also cause problems.

Corporate performance, therefore, is a result of environmental forces and capabilities developed within firms (Withers et al., 2018), but they are not responsible for creating the organizational strategy, people are responsible for that. One of the mechanisms that influence this process consists of the paradigms (Johnson, 1992). Explaining that: internal and external aspects of the organization certainly affect, individually, how managers perceive the facts, which directly affects the decision-making guidance. Such interpretive bias can be illustrated by the daily fact 
of two different viewers seeing the same move in a soccer game differently or analyzing a single investment decision on the stock exchange in opposite ways. The process is then repeated for several cultural artifacts: organizational routines, rituals, and existing formal controls.

\subsection{Skewed Decision Making}

Facing changing circumstances, executives tend to cope better with situations that are aligned with their paradigms, with cultural and other social and political aspects prevailing in the organization. That hampers the decision-making to escape from such a context. Thus, managers will always tend, firstly, to change what does not escape the current paradigm, to eliminate information that does not comply with it and to absorb information that is aligned with it. However, this bias, over time, makes the company's strategy become increasingly detached from environmental changes, in a process that is neglected by managers until it begins to affect the results.

The effect of this process is that the organization tends to develop strategies aligned with its managers' points of view and not with what actually occurs in the environment. However, paradoxically, environmental forces will affect the company's performance and jeopardize its outcomes over time.

Cognition resource is a concept extensively explored in psychology and behavioral economics. In the context of this study, the concept is useful to unite the theory of paradigm and culture to the concepts of dynamic capabilities. Therefore, its definition is of extreme value to the case being examined. However, what does the term mean? What are its implications? Objectively, cognitive resources mean identifying resources and the understanding of their fungibility, resulting in resource schemes, i.e., mental models that managers apply in their companies and determine which are the observed resources and what are their potential applications in a subjective process of choices and identification (Danneels, 2010; Teece, 1982; Prahalad and Hamel, 1994) valuable for the purpose of this study.

\section{METHODOLOGY}

Case studies are appropriate when questions like "how" and "why" are presented, when the researcher has little control over events, and when the focus is on contemporary phenomena that occur in the real context (Yin, 2001). They are particularly interesting because there is little information about the variables, several pieces of evidence able to provide a triangulation of data and previous theoretical propositions able to guide the collection of data (Yin, 2001). Such is the case in this study, which used the procedures proposed by Yin (2001).

The publishing house is a particularly interesting unit of analysis for the purposes of this study because it consists of a family business with a very strong culture and well-established routines that have been operating in the publishing market since 1950, being the pioneer in the development of crosswords and hobbies magazines in Brazil. Through this case is possible to identify how the family firms are different in terms of culture and organizational routines if compared with nonfamily firms. This occurs because family founders' early experiences, feelings, and emotions may be imprinted on the firm, more than in nonfamily firms (Stanley, 2010). The family firm business culture has been crucial for family business success using dynamic capabilities in changing environments (Chirico, 2007). Also, the success of the family firm can be achieved by developing strategies that promote change and innovation (Miller, 1983). 
BBR

17

298

As the object of analysis, we used in-depth interviews with the managing partners of the company (which, due to ethical issues, will be referred to as interviewed 1, interviewed 2 and interviewed 3), as well as financial balance sheets, income statements of the considered years, and market monitoring reports provided by the company.

Firstly, concepts have been developed that involve the constructs used: the four dimensions in the development of dynamic capabilities proposed by Eisenhardt and Martin (2000) - resources leverage, creating new resources, access to external resources, and resource saving - which is associated with a fifth dimension, proposed by Danneels (2010). These dimensions were joined also to the paradigm construct, from the perspective of the literature on strategic change developed in the theoretical framework and other references that were necessary during the analysis of the material.

Altogether, there were six in-depth interviews with three of the four company's managers in the last 20 years. There was a space of six months between one interview and another with each manager. Then, the data were encoded and confronted with the studied literature and the financial and economic data provided.

\section{A PUBLISHING HOUSE CASE STUDY}

\subsection{A Brief History of THe PUblishing house}

Founded in October 1950, in São Paulo, the publishing house is the realization of the dream of its founder, a great admirer of Italian hobbies magazines, his great companions during the period lived in Italy in early childhood. Feeling that there was nothing like that in Brazil, he then founded the firm, the first magazine of crosswords in Brazil. Historically, the company has a lean staff, with ten employees, which allows it to have a simple structure composed of two sectors: administrative and creation. The rest of the activity is outsourced to specialized service providers.

The company over its decades of existence has built a very loyal customer base, some of them collect the magazines since the first edition. However, certain environmental changes - including the development of new habits of the elderly population, aging of its readers, and the difficulty to renew the target audience - have led to an overall drop in sales of the firm products in the past 15 years. The company, accustomed to the stability of five decades without acute crises, must act to survive.

Over the past 15 years, the publishing house sought to remain faithful to its tradition of producing hobbies magazines with high levels of culture, focusing on the strategy of launching new titles on the market with the same features supported from the beginning of its publications. Thus, through a greater targeting by types of hobby and sub-levels of difficulty (always from intermediate to difficult), the goal was to attract a new audience - especially readers of the magazine Coquetel. Later, it also created children's titles and offered hobbies similar to the magazine Coquetel, relying on the fungibility of its brand and on the perception that its image quality would transpose from its segment to the entire market. Other attempts have also been made but have not achieved the expected effects.

This longitudinal case study covers the last 20 years of history of this publishing house from the perspective of the difficulties that the weight of tradition imposes and trying to understand why the publishing house has not succeeded until the present time, in order to meet the new demands that the dynamic market has imposed. Therefore, we are guided by the theoretical 
framework that seeks to answer the question: how organizational paradigms skew the choice of which dynamic capabilities should be developed in organizations?

The history of the publishing house demonstrates that the company has achieved great success and met the demands of the market for over five decades. However, in the last 15 years, the publishing company has found it difficult to readjust to the changes and restore its old financial level, at risk of death. That is, considering its life cycle, the company is in a declining phase and needs to reverse this situation. As mentioned above, various attempts have been made, but without success.

Under the theory of dynamic capabilities, the next section is organized considering the four dimensions in which the resource base of a company can be changed (Eisenhardt and Martin, 2000) and the fifth dimension proposed by Danneels (2010). It is intended to draw a general parallel with the evolution of the paradigm in the company and its financial performance in the last 20 years.

\subsection{LEVERAGING EXISTING RESOURCES}

Leveraging existing resources means to apply the current resources in new forms of use. Resources can be categorized into two different types: those related to the market and those related to technology.

The publishing house, over the first five decades of its existence, has developed the ability to create new products whenever there was a change in its financial results, going unscathed through Brazilian historical moments - such as the freezing of the tax rates during Collor's mandate - and having the ability to release parallel titles whenever the situation demanded. The know-how in this type of activity, of technological character, is so great that the company, from one month to another, can assemble and disassemble a production line while maintaining the desired quality, as stated by the respondent 2: "Over the years, passing by the difficulties imposed by the freezing of the prices during Collor's mandate, mainly, we learned how to build a very flexible team, consisting of dozens of employees working on demand, with extensive experience." However, once questioned whether these products reached a new audience, the three managers were emphatic in saying that the publishing company never had to worry about attracting more consumers, because it had a loyal customer base who were in charge, by themselves, to disseminate magazines between friends and relatives. "The case of the publishing house is amazing. I never met a company with such a loyal customer base. Some of them have even left their inheritance to the publishing house because they see it as a life mate" added interviewee 2. This belief demonstrates how the company coped well with the technology to manage the crises and fluctuations it came across with, but it neglected the external situations that have occurred in the market. In this sense, interviewee 2 also said:

We never bothered to do analysis or even worrying about the price competition. Even today, I think the magazine of the publishing house has no direct connection with any other product in the market [...]. We have our audience, and other companies have theirs. We just did not find the way to deal with the renewal of our audience, because I am sure an audience will always exist.

Consumer knowledge reflects an integrated mental model of identity, needs, lifestyle, and behaviors (Danneels, 2003). In the excerpt above, it is possible to observe how the company's paradigm about the knowledge of their consumer is influenced by a certain bias. When launching new products, the editors thought that only their current readers would be a sufficient basis to 
reach new audiences by indicating among their acquaintances. However, this perception has become flawed, likely on two main aspects: consumers were not willing to present the products to friends and/or friends were not willing to know the new products, which occurs for several aspects related to mental model and social behavior that have been transformed over the years.

The company, FC Comercial, the oldest client, has distributed the publishing house materials nationwide. When launching new products, the firm believed it could use the relationship built over six decades for support. However, what happened was that in the launching meantime, the distributor was hit by a major crisis and sold to another company in the segment, DINAP, which together formed a monopoly in the Brazilian market of magazine distribution. In this new reality, the publishing company lost its historical bargaining power with the supplier and came to be seen as just another customer. Important contractual changes were made and the operating costs of the distribution process have grown a lot as well as the minimum conditions of sale. Based on that, the publishing company was gradually forced to keep only profitable products, since the distributor refused to invest in new titles, as it was in crisis. Respondent 3 said:

We thought we would have the support of FC to launch new titles. Magazines are unpredictable. You have to launch and bet on it for at least six numbers to check if the market responds to it. They did not give us that chance and increased the fine values for not achieving minimum standards for sale. Then, it was difficult.

Besides launching new products in its category, the publishing house sought new alternatives that were within the scope of the current paradigm of the company, which is to be a publishing company of printed crosswords. Thus, it developed a strategy of brand extension defined by the use of existing brands to enter new product categories (Keller and Aaker, 1992 apud Danneels, 2010). According to the authors, three types of brand associations affect the fungibility of a brand: associations to product categories (crosswords), associations to benefits (quality) and associations for usability (fun).

The publishing house has chosen to offer content to the market by selling targeted issues, namely the sale of content for special corporate projects, such as educational campaigns and targeted magazine publishing (exclusively for sale in certain networks, published with the network brand). According to the respondent 3: "We knew that newsstand sales worked against us, the numbers fell steadily, while the operating costs of distribution only increased. We reached a moment when it became clear that we could not think only in newsstand selling anymore." Persisting in the organizational paradigm, the company opted again for incremental innovation. However, the managerial decision on the brand fungibility proved to be ineffective again, as the only brand association that has been shown in practice, was the one to product category.

\footnotetext{
We thought that by launching new products we could transpose them to our image of quality since our competitor had a quantitative view, but I do not know what happened, we could not achieve the market support we thought we would. People recognized us as an important brand, received us well, but we kept losing the bids we were taking part, even at prices below the table (Interviewee 3).
}

Clearly, new customers did not notice the new category of products developed by the firm as something to bring any additional benefits to what was already in the market. That is, the products, despite the brand recognition, did not add any value. What was done within its niche was not fungible to new categories. 
Being unable to exercise the ability to leverage existing resources, organizations should seek the ability to create new resources that together form a new competence (Grant, 1991 apud Danneels, 2010). In this dimension, the publishing house proved to be unskillful. According to the respondent 1: "We have always known that what we had to do was within our competence, which is developing crossword puzzles and hobbies magazines of quality, with a lot of content." Respondent 3 complements: "To this day, I have believed that thinking differently is losing focus. All of us here think so." As noted, managers share the same view, to date, that the company should focus on incremental innovation, and that the development of new capabilities that generate new skills is treated as negative for the company, to be associated with loss of focus on the competence to produce quality hobbies magazines with relevant content.

This paradigm corroborated that the company did not spend time developing structured forms, able to build dynamic capability linked to the creation of new resources, which led to a misalignment between the organization and the environment in the process mentioned in the theoretical framework. It can be inferred, as it is in a very dynamic environment, that the company managed to perpetuate for decades without this ability; however, when there was a significant environmental change, the company began to rely only on existing resources, inadequate to the new context.

It can be noted by analyzing the company's balance sheets, that the lack of focus on innovation is not related to a lack of financial resources, being linked to the paradigm of the organization's managers that innovations should be incremental and within existing competencies. Interviewee 2 states: "We know well the business, we do not lose money with surveys and other things. We have to keep the company financially healthy." It is evident the notion that only spending less means "keep the company healthy." Interviewee 1 adds: "Over time we have learned how to save. This is one reason for the company's success to date." It is highlighted that despite the drop in sales and sharply declining financial outcomes, the company's managers still have a successful view of how the management is carried out.

\subsection{ACCESSING EXTERNAL RESOURCES}

According to the classification we have chosen, another strategy to modify the basic resources of an organization is to access resources outside the organization. Alliances and acquisitions are two ways to apply that (Eisenhardt and Martin, 2000). The publishing house, over the process of falling sales and profit margins, used its financial fund to invest in the books segment, buying an on-demand book printing company. For contractual issues, this company will be kept anonymous in this article, simply referred to as New Book publishing house. According to the respondent 2, the expectation was "to buy an established company to adapt it to the culture of the firm with no risks", i.e. to associate complementary resources to the existing ones in order to develop new skills in the future, the firm offered, as resources for the New Book publishing house, money to accelerate its development, and its distribution contacts network, spreading the distribution of books, which would be done through the newsstands channel. New Book offered, as cited above, new resources that could generate new skills in a new market of interest: the independent book market. The plan proved to be impracticable.

New Book was started by the initiative of two young partners who noticed a shortage in books printing on demand for authors interested in publishing their work and with difficulties or aversion to seeking major publishing companies. Based on success stories on this model known by one of the partners who resided temporarily abroad, the publishing firm decided to invest, 
without much planning, and only intuitively, according to the consensus among the partners. In the first months, however, the incompatibility between the decision-making mental model of this publishing house's managers and New Book managers became evident, which made the decision making of the company - still a startup - slow for founders and very dynamic for managers of the firm. It did not take long for the first insoluble disputes start, as stated by the respondent 3:

\footnotetext{
It was not possible. At first, the boys seemed willing to follow a slow and safe development, as we are accustomed to. However, in the first months, it became clear that they were still children, who had not much more than a good idea in their heads. We lost a few hundred thousand reais but we decided to get out of that business, we did not fit in. We were in a difficult situation.
}

In addition, the initial expansion plans were costlier than originally thought and the changes relating to the merger of FC Comercial distributor made unviable the distribution plans through newsstands. Thus, unlike what the managers had thought at the beginning of the process, mutual funds became uninteresting for both, making the situation even more difficult. "We reached a moment when our partnership made any sense no longer. We could not stand each other anymore" said respondent 1 . The publishing house encountered the most fundamental premise for the success of alliances or acquisitions process "Companies need to have resources to find resources "(Eisenhardt and Schoonhoven, 1996 apud Danneels, 1996).

These facts denote apparently hasty attitudes to seeking resources through acquisitions, without paying attention to basic issues, highlighting the company's inability to access external resources through acquisitions and mergers.

\subsection{SAVING RESOURCES}

Saving resources are the last of dynamic capabilities (Eisenhardt and Martin, 2000) that the traditional literature addresses. That capacity was exercised more often in the company over the analysis period. However, what is happening is that, despite the concern of managers to work with the least possible resources, it contributes negatively to the innovation process, as it frequently prevents more suitable processes for new resources creation from being developed, or for the existing resources advantage.

To leverage existing resources, based on the incremental logic of low dynamic markets, it is an assumed process that uses past data capable of generating more structured plans for the company. However, as mentioned before, interviewee 2 said "we know well the business, we do not lose money with surveys and other things. We have to keep the company financially healthy." That is, there is a consensus that executives know the business so well that only an intuitive management is enough.

As implications of the new resources created, excerpts cited in the joint interview with managers are emblematic to demonstrate the company's culture. When asked about how they perceive the constant drop in sales in relation to environmental changes, statements such as "we are competent making and printing crosswords, there will always be people who like paper and letters", "I do not believe the computer will make our market disappear. Children are literate with pencil and paper, even with so much technology" and "every experience outside our area of expertise was catastrophic" demonstrate how the paradigm of the organization's managers remains that the publishing house is a company of printed crosswords and should remain so.

An important point is that, despite the historical resources saving, the organization does not invest in improvements. Says the interviewee 3: "the whole family depends on this business; we 
have to show outcomes. Our business is stable; we do not spend money on this. Someday we will find the way." Statements like this show that the resource saving has only the function to bring immediate benefits to the partners, and it does not exercise the strategic role of seeking improvements and the company's survival over time. Apparently, it depends exclusively on luck.

\subsection{Cognition of Resources}

Danneels (2010) proposes and empirically tests a new dimension which can change all the other company's resources, called cognition of resources. Its premise is the following: to understand how companies exercise their dynamic capabilities, it is necessary first to consider how their executives exercise and see them.

Cognition of resources is a concept extensively explored in psychology and behavioral economics and refers to the identification of resources and the understanding of fungibility, resulting in resource schemes, or mental models, that managers apply in their businesses and determine what resources are perceived, the potential applications of those resources, in a subjective process of choices and identification (Danneels, 2010; Teece, 1982; Prahalad and Hamel, 1994).

In the publishing house's case, even before the facts demonstrated by the financial results of the company, internal and environmental issues - such as changes in habits of the elderly population - the advent of new technologies and falling revenue and profit margins, there is a belief that the logic of incremental change is the only way for the company to reverse the situation. That influences how the company managers see and make decisions about how and what dynamic capabilities the company needs to develop to change their resource bases. The managers of the organization show they do not believe in the gradual extinction of the magazine publishing market, or the potential for crosswords to be replaced by other forms of leisure and culture, which is decisive in how they exercise their dynamic capabilities. In the case of this publishing house, it was invested only in existing resources leveraging - yet, in an unstructured way - assuming the attraction of external resources as a threat to the current paradigm, saving resources only for partners' immediate benefits, and the new resources creation as something negative that deviates the company's focus from its core business: to produce printed crosswords and hobbies magazines.

\section{DISCUSSION}

Based on the understanding of the concepts related to dynamic capabilities, we intended to collaborate with the gap theory proposed by Danneels (2010), arguing that only structured plans and routines are not enough to adequately guide the process of strategic change in organizations. Because of its complexity, it is important to consider the environmental issues able to influence it.

The theory tells us that, before changes, executives tend to cope better with situations that are aligned to their paradigms, culture, and other sociopolitical aspects in the organization, and the trend is always to seek for innovation through what does not flee to such aspects, eliminating information that does not comply with them and absorbing information that corroborates (Grinyer and Spender, 1979).

The presented case empirically analyzes this theoretical question and demonstrates the importance of the organizational paradigm in the decision process about which dynamic capabilities the organization develops or not, which is a relevant factor in the result of the study of how some organizations survive environmental changes while others succumb. 
Some questions must be answered when studying dynamic capabilities, important theoretical issues to the adequacy of the analysis model. The first is: to what extent innovation in the company is truly held by dynamic capabilities? Let us explain: the theory shows that, to exert dynamic capabilities, it demands both a routine and a well-defined goal (Winter, 2003). Some of the key mechanisms of learning to exercise it is repeated practice, the codification of experience, and by learning with mistakes, and the experience speed (Zollo \& Singh, 1998), and, as it gains knowledge in the process, it tends to turn into progressively more formalized routines so that they can achieve their goal more effectively. The case study, however, shows that, in general, the managers of the firm act intuitively, without any formal long-term planning, which prevents them from exercising strategic decision process in a structured way, as it is suggested to low dynamic markets (Helfat, 1997).

Still, it is noticeable that, in some cases, even without the use of technical tools, managers have developed one of the proposed dynamic capabilities very well in the company: the leverage of existing resources. This is because the company has gone through previous crises that imposed the need to develop it, such as the freezing of the prices during Collor's mandate, creating a process repeated several times that allowed the company to encode experiences and learn from errors in order to gradually develop an effective process to create new products for its existing audience. We understand that this fact has allowed the company to prolong its life cycle successfully.

Logical incrementalism assumes that the company's strategy is developed incrementally into a model, in which the past is very important in the way the company shapes the future (Quinn, 1980). Based on this concept, it is suggested that this alleged success at leveraging existing resources corroborated to build a strong paradigm (Johnson et al., 2003) that acts negatively, preventing the development of another key dimension of dynamic capabilities offered by Eisenhardt and Martin (2000): the creation of new resources. In this process, the historical view that the only existing resources advantage is enough to maintain the company healthily strengthened the organizational paradigm and did not allow managers to make truly innovative decisions, and to create new resources in order to develop new skills. As it went through its life cycle, these skills were not necessary, becoming evident only when the environment demanded changes, revealing them as critical success factors. However, it is a capability the company has not developed yet.

It is important to consider that formation of the current paradigm and the analysis from the perspective of logical incrementalism the company's experience in trying to exercise the third of the dynamic capabilities dimensions (Eisenhardt and Martin, 2000): the acquisition of external resources. In seeking to grow to acquire new skills quickly, looking for work in a new segment, the company had an unsuccessful experience. The publishing house's managers, without previous experience, just based on personal perception and opinions shared - that is, in the paradigms, have made the acquisition of the publishing house New Book, relying on assumptions that were not true.

In the end, the publishing house could not offer the resources that interested the New Book partners, such as comprehensive distribution on newsstands and financial resources, as well, New Book could not offer a business model that would fit the paradigm of the managers. There was not a relationship based on resource exchange, as it is required in a resource acquisition relationship, and therefore the partnership lost sense. The point is that managers did not see the situation that way and closed the company to new partnerships, attributing a negative connotation to such type of effort, rather than trying to codify experience, learn from mistakes and seek new ways to develop the dynamic capability to acquire resources. 
The case analysis makes clear that the organizational paradigms skew the choice of which dynamic capabilities should be developed, prioritizing those that are in accordance with the organizational paradigm. Therefore, the organization tends to be aligned with its own paradigm, rather than aligning with context.

In other words, the environmental changes, with the changes of habit, routine and profile of elderly Brazilians, endangers the survival of the publishing house. The study demonstrates the need to develop dynamic capabilities to meet these environmental changes. However, it was shown that the managers' mental model of decision making, affected by the organizational paradigm, is a disincentive for this to occur, causing the organization to align with this paradigm and not with the environment effectively. That is the main contribution of this work: it demonstrated how this process occurs.

In this process, managers tend to consider information that reinforces their beliefs - like the fact that the elderly population is growing - and disregard environmental information that does not align with their paradigm: for example, the fact that the market for printed magazines, despite the expansion of the Brazilian base with sufficient purchasing power to invest in leisure, decreases by an average of $3 \%$ per year, and that the elderly today have new habits and expectations. The process directly influences the managers' strategic decision-making and, consequently, the choice of which dynamic capabilities the company will develop.

As said before, this phenomenon is called by Danneels (2010) resource scheme, i.e., simplifying mental models of reality that managers adopt in their companies to cope with the complexity and manage their resources, containing answers to questions that will lead the application of resources through their particular point of view and logic. However, since they are simplistic models, they may omit important and decisive details in the direction of the organization (Danneels, 2010), as demonstrated by the example discussed here and the clarity of opinions issued by the company managers who believe it should not seek other opportunities besides those related to its current competence: to produce printed crosswords magazines. Therefore, they do not consider the environmental information that is not according to it and consider others that support a distorted mental model view, which dangerously affect the organization.

The saving of resources was evident in the case study as a common practice in the activities of the business. However, to ascertain the purpose of such an action, it is clear that there is a certain strategic role: it is used only as a way to generate more profit distribution to shareholders, for private purposes. Still, we understand that this can be considered a dynamic capability as it meets the requirements proposed by Winter (2003) and Zollo and Singh (1998).

Looking at the context, we can infer that this is an example of the bias of the choices in the decision-making process of managers, because the environment requires the company to reinvent itself and develop new skills, but even so, the mental model enhanced by the paradigm of managers sees the investment in creating new resources as negative, simply as a waste. This shows that the organizational paradigms make the company tend to align more with their own paradigms than the environment's, skewing the choice of which dynamic capabilities must be developed in order to be able to promote the changes, and then the necessary innovation to prevent it from a decline - in the case of the publishing house. So, that it gets out of a declining situation in its life cycle.

Premised on all four dimensions of dynamic capabilities (Eisenhardt and Martin, 2000), the fifth dimension proposed by Danneels (2010), the cognition of resources, which is directly related to the concept of resource schemes. We sought evidence in the analysis of each of them as the 
BBR

17

306

managers' mental model of decision-making directly influences the choice of which dynamic capabilities should be developed in the organization. Our goal was to empirically demonstrate how cognition of resources influence which dynamic capabilities an organization develops. The empirical result was as follows: the power of paradigms makes the organization align increasingly with itself by disconnecting gradually from the environment.

Today, the publishing house continues to suffer from the fall of its revenue, keeping alive with the significant contribution of dynamic capabilities that it has developed over its history: the leverage of existing resources and resource savings. However, it seems unable to reinvent itself due to the challenges imposed by the environment today to the publishing houses of print crosswords magazines, precisely by not seeking new skills and being, somehow, skewed by the mental scheme built to over its nearly 65 years of experience, which shows the weight of tradition.

\section{CONTRIBUTIONS}

The publishing house was able to leverage its resources when faced with crises in past decades, but the same situation is not perceived in the present times. The managers' statements, demonstrated through the fragments presented in the results, show that they have a market-based view based on the success of the past. Although it currently maintains a resource economics dimension, which can be questioned from the conceptual point of view of dynamic capabilities, the company does not sketch any reaction regarding technological change that has promoted radical changes in the behavior of all age groups of the population. On the other hand, although the current moment of the company does not portray constant performance of dynamic capacity, really the company is only currently active due to its actions of dynamic capabilities held in the past. The construct created relates the present moment of the company with the dimensions of the dynamic capacities that the company has played in the past.

Although the company did not fully integrate itself into the digital world, to have a platform for reading its editions digitally, this does not detract from all the other aspects pointed out in the case, the secondary ones and the primary ones. Nowadays, it can even be inferred that, because the most abrupt technological changes are not priorities for the company, it maintains readers with a more advanced age profile, which would be more reticent on the part of these, if changes occurred, justifying the managers' speech with more reticent behavior in proposing drastic changes.

\section{FINAL CONSIDERATIONS}

Usually limitations are present in the most varied scientific study styles. This case is no different. As a main limitation, we point out that this is a single case study. On the other hand, the purpose of the analysis is not to provide a highly generalizable result, but rather to widen our knowledge of the variety of strategies mechanisms. With that in mind, while this paper does not allow the reader to generalize the main findings here reported, it still shed lights on implications of strategy and culture organization in a way that could provide new insights for future quantitative studies. Therefore, further studies could be developed by analyzing this results in a different context in a qualitative or quantitative approach.

As effective research is one that can contribute to the segment studied, it is important to point out possible ways for the company's reaction to the environment, including those that are vital to the survival of the company. One of these would be the change of product distribution platform 
or even the renewal of the management team, because, as seen the reports of the interviewees, managers have a conservative profile and little or no ability with the digital world. Therefore, one of the alternatives would be the availability of products already existing in applications through digital channels, as seen with applications of magazines in national circulation, even with the partnership between mobile phone operators. In this case, it is not about radical product innovation, only the building of partnerships for the modification of the distribution platform.

\section{REFERENCES}

Argote, L. (1999), Organizational learning: creating, retaining, and transferring knowledge. Kluwer Academic Publishers, Boston.

Breznik, L. \& Hisrich, R. D. (2014), Dynamic capabilities vs. innovation capability: are they related?, Journal of Small Business and Enterprise Development, 21(3), pp.368-384.

Brown, S. L. \& Eisenhardt, K. M. (1997), The art of continuous change: linking complexity theory and time-paced evolution in relentlessly shifting organizations, Administrative Science Quarterly, 42, pp. 1-34.

Chirico, F. (2007), The Value Creation Process in Family Firms. A Dynamic Capabilities Approach, Electronic Journal of Family Business Studies, 1.

Cyert, R. M. \& March, J. G. (1963), A behavioral theory of the firm. Englewood Cliffs, Prentice Hall, NJ.

Danneels, E. (1996), Market segmentation: normative model versus business reality, European Journal of Marketing, 30(6), pp. 36-51.

Danneels, E. (2003), Tight-loose coupling with customers: the enactment of customer orientation, Strategic Management Journal, 24(6), pp. 559-576.

Danneels, E. (2010), Trying to become a different type of company; dynamic capability at Smith Corona, Strategic Management Journal, 32, pp. 235-264.

Eisenhardt, K. M. (1989), Building theories from case study research, Academy of Management Review, 14(4), pp. 532-550.

Eisenhardt, K. M. \& Martin, J. A. (2000), Dynamic capabilities: what are they?, Strategic Management Journal, 21, pp. 1105-1121.

Eisenhardt, K. M. \& Sull, D. (2001), What is strategy in the new economy?, Harvard Business Review, 79(1), pp. 106-117.

Eisenhardt, K. M. \& Tabrizi, B. N. (1994), Accelerating adaptive processes: product innovation in the global computer industry, Administrative Science Quarterly, Vol. 40, pp. 84-110.

Floyd, S. W., \& Lane, P. J. (2000), Strategizing throughout the organization: managing role conflict in strategic renewal, Academy of Management Review, 25(1), pp. 154-177.

Fredrickson, J. W. (1984), The comprehensiveness of strategic decision processes: extension, observations, future directions, Academy of Management Journal, 27, pp. 445-466.

Grinyer, P. H. \& Spender, J. C. (1979). Recipes, crises, and adaptation in mature businesses. Int. Studies of Mgt. \& Org., 9(3), pp. 113-133.

Hamel, G. and Prahalad, C. (1994), Competing for the future, Harvard Business Review Press, Boston. 
BBR

17

308

Helfat, C. E. (1997), Know-how and asset complementarity and dynamic capability accumulation: the case of R\&D, Strategic Management Journal, 18(5), pp. 339-360.

Lynch, S. E. \& Mors, M. (2019), Strategy implementation and organizational change: How formal reorganization affects professional networks, Long Range Planning, 52(2), pp. 255-270.

Johnson, G. (1992), Managing strategic change, strategy, culture and action, Long Range Planning, Vol. 25, No. 1, pp. 28-36.

Johnson, G., Melin, L. \& Whittington, R. (2003), Guest editors' introduction: micro strategy and strategizing: towards an activity-based view, Journal of Management Studies, 40(1), pp. 3-22.

Miller, D. (1983). The correlates of entrepreneurship in three types of firms. Management Science 29(7), pp.770-791.

Nelson, R. R. \& Winter, S. G. (1982), An evolutionary theory of economic change. Belknap, Boston.

Pedron, C. D., Picoto, W. N., Colaco, M., \& Araújo, C. C. (2018). CRM System: The Role of Dynamic Capabilities in creating Innovation Capability. Brazilian Business Review, 15(5), 494-511.

Pettigrew, A. M. (1985), Contextualist research and the study of organizational change processes, in E. Lawler (Ed.). Doing research that is useful for theory and practice, Jossey Bass, San Francisco, pp. 53-72.

Quinn, J. B. (1980), Strategies for change: logical incrementalism. Homewook, Irwin, Illinois.

Schein, E. H. (1986), Organizational culture and leadership, Jossey Bass, San Francisco.

Sitkin, S. B. (1992), Learning through failure: the strategy of small losses, Research in Organizational Behavior, 14, pp. 231-266.

Stanley, L. J. (2010), Emotions and Family Business Creation: An Extension and Implications, Entrepreneurship Theory and Practice, 24, pp. 1085-1092.

Teece, D. J. (1982). Towns an economic theory of the multiproduct firm, Journal of Economic Behavior and Organization, 3, pp. 39-63.

Teece, D. J., Pisano, G. \& Schuen, A. (1997), Dynamic capabilities and strategic management, Strategic Management Journal, 18(7), pp. 509-533.

Tondolo, V. A., \& Bitencourt, C. C. (2014). Understanding Dynamic Capabilities from Its Antecedents, Processes and Outcomes. Brazilian Business Review, 11(5), 122-144.

Wang, Y. (2016). Investigating dynamic capabilities of family businesses in China: a social capital perspective, Journal of Small Business and Enterprise Development, 23(4), pp.1057-1080.

Winter, S. G. (2003), Understanding Dynamic Capabilities, Strategic Management Journal, 10, pp. 991-995.

Withers, M. C., Ireland, R. D., Miller, D., Harrison, J. S., \& Boss, D. S. (2018). Competitive Landscape Shifts: The Influence of Strategic Entrepreneurship on Shifts in Market Commonality, Academy of Management Review, 43(3), pp. 349-370.

Yin, R. K. (2001), Estudo de caso: planejamento e métodos (2a ed), Bookman, Porto Alegre.

Zollo, M. \& H. Singh. (1998), The impact of knowledge codification, experience trajectories and integration strategies on the performance of corporate acquisitions, Academy of Management Best Paper Proceedings, San Diego, CA. 